\title{
THE ICD-11 FOR THE TWENTY-FIRST CENTURY: THE FIRST VIEW FROM THE ORGANIZATIONAL, LEGAL, CLINICAL AND PHARMACOLOGICAL ASPECTS
}

\author{
Viktoriia Shapovalova ${ }^{1}$ (Doctor of Pharmaceutical \\ Sciences, Professor) \\ ${ }^{1}$ Kharkiv Medical Academy of Postgraduate Education, \\ Kharkiv, Ukraine) \\ *Corresponding author: Viktoriia Shapovalova
}

Received: January 04, 2022

Published: January 18, 2022
Abstract. The author made an organizational and legal, clinical and pharmacological study of the latest International Classification of Diseases (ICD-11) concerning its changes compared to the ICD-10. Particular attention was paid to new ways of marking of disease codes and new functions of the ICD-11. Novel structure based on cluster coding, which was implemented into the new revision was mentioned, which allows to connect the main diagnostic codes with advanced clinical indicators. Author found that for the first time, the new revision has become a fully electronic publication that provides access to more than 17,000 diagnostic categories that contain more than hundred thousand of terms of the medical diagnostic index. The new ICD-11 concept of linearization for the national needs of each country was taken into account, which will save budget expenditures for the future. In the new edition of the ICD-11, for the first time, gambling addiction is classified as a mental disorder - behavioral addiction to online and offline gambling. The list of ICD11 short stories also includes the classification of the following: chronic pain, burnout, stroke, sexual health, post-traumatic stress disorder, allergies, alternative medicine, etc. It is a more powerful health information system based on a formal ontology, designed to integrate information technology into modern infrastructures. A comparison with the ICD-10 on mental and behavioral disorders due to the use of psychoactive substances was made. The ICD-11 has been identified as having a more comprehensive list of disease diagnosis codes, and in the ICD-10, the section on mental and behavioral disorders due to substance use has eleven core codes. Indicated the prospects of using of the ICD-11 in medical practice.

Keywords: ICD-11, classification of diseases, psychoactive substances, mental and behavioral health disorders, clinical pharmacy, organization and management of pharmacy.

Introduction. The World Health Organization presented a new edition of the International Classification of Diseases $11^{\text {th }}$ Revision (ICD-11) at the World Health Assembly on May 20, 2019 in Geneva. The ICD-11 is the most complete, systematic list of known and recognized evidence-based diseases and conditions [1].

The ICD-11 will enter into force after consultation with all WHO countries [2].

Thus, classifications of mental disorders change regularly. This fact requires analysis taking into account changes in the epidemiological situation and 
organizational structure of psychiatric care, the development of its technical and human resources [3].

The development of the ICD-11 by the European Committee on Democracy and Governance (CDDG) for mental and behavioral disorders based on statistical classification is the first major revision of the world's leading classification of mental disorders in almost 30 years. Significant changes have been made to increase the scientific validity and clinical usefulness of health statistics, and the CDDG has been made to be used in clinical settings by mental health professionals. The WHO notes that the implementation of the ICD-11 involves the interaction of classification with the rule of law, laws, national policies, health systems and information infrastructure of each country. Training methods need to be developed for a wide range of international health professionals [4].

The purpose of the work was to conduct an organizational, legal, clinical and pharmacological study of the ICD-11 concerning the changes, new ways of labeling disease codes, new functions, electronic resources; compare with the Diagnostic and Statistical Manual of Mental Disorders (DSM); compare it with ICD-10 on mental and behavioral disorders from the use of psychoactive substances (surfactants).

Materials and methods. The methodological basis of the study was based on the paradigm of organizational and legal, clinical and pharmacological standards: ICD11; ICD-10; DSM-5; CDDG materials; materials of the American Psychological Association; international and national medical and technological documents on standardization of medical care; normative documents (standards of medical care, clinical protocols, forms of medicines, National list of essential medicines, instructions for medical use); scientific publications on the topic of work [5-10].

More than seventy legislative, normative and legal, instructive and methodical documents have been processed. Methods of clinical and pharmacological, normative and legal, retrospective, documentary, comparative, system and graphic analysis are used [11-18].

The research of the article is a fragment of research work of the Kharkiv Medical Academy of Postgraduate Education on "Improving the organizational and legal procedure for providing patients with drugs from the standpoint of forensic pharmacy, organization and management of pharmacy" (state registration number 0116U003137, terms 2016-2020) and "Pharmaceutical and medical law: integrated approaches to the system of drug circulation from the standpoint of forensic pharmacy, organization and management of pharmacy" (state registration number 0121U000031, terms 20212026) [19-32].

Results and discussion. Modern psychiatry is replete with a variety of methodological paradoxes. The main thing is the lack of scientific persuasiveness of the procedure for including mental and behavioral disorders in diagnostic systems. In the absence of progress in understanding the mechanisms of etiopathogenesis, the number of diagnoses continues to increase. All new clinical phenomena pass from the number of deviations to the category of mental disorders. In the first classification of DSM-I, published in 1952, there were 106 diagnoses, in the modern DSM-5 - already 282 [33]. The psychiatric section of ICD-10 contains about 300 diagnoses. The ICD- 
11 includes additional diagnostic units mainly from the group of behavioral and addictive pathology - pathological accumulation (holding), compulsive overeating, etc. [34].

The ICD-11 diagnostic codes are alphanumeric and cover the range from $1 \mathrm{~A} 00.00$ to ZZ9Z.ZZ. The coding scheme always has a letter in the second position to distinguish it from ICD-10 codes. Chapters are indicated by the first symbol. The ICD11 has an explicit way of marking codes that are post-coordinated to describe a single condition called cluster coding. This is a notable new feature in the ICD-11 that creates the ability to link core diagnostic concepts (i.e., core code concepts) and add clinical concepts captured in extension codes to core code concepts. In any case, it should be emphasized that the clustering ability inherent in the ICD-11 is one of the significant changes compared to the ICD-10. WHO indicates that there may not be a need for a version of ICD-12, as ICD-11 is comprehensive and very expanded. In addition, for the first time, ICD-11 will be a fully electronic publication, providing access to 17,000 diagnostic categories containing over 100,000 medical diagnostic index terms. The index-based search algorithm interprets over 1.6 million terms. According to WHO, ICD-11 is easy to install and use online or offline using free "containerized" software [35].

The American Psychological Association (APA) is a scientific and professional organization that represents psychologists in the United States. The American Psychiatric Association has published the 5th edition of its Diagnostic and Statistical Manual of Mental Disorders (DSM-5). During the development of the ICD-11 and DSM-5, the World Health Organization and APA made efforts to harmonize the two systems (ICD and DSM). ICD-11 contains 19 categories of health disorders that do not appear in DSM-5, but seven categories of DSM-5 disorders do not appear in the ICD11. In the literature, there are data on the basic characteristics in the ICD-11 and Clinical Descriptions and Diagnostic Recommendations (CDDG) with DSM-5 criteria sets for 103 diagnostic objects that are present in both systems. Science resources show, that 20 disorders $(19.4 \%)$ have large differences; 42 disorders $(40.8 \%)$ - minor differences in definitions; 10 disorders $(9.7 \%)$ - minor differences due to greater granularity in DSM-5; 31 disorders (30.1\%) are almost identical. ICD-11 and DSM-5 are now closer than ever since ICD-8 and DSM-2. The differences are largely based on different priorities and use of the two diagnostic systems, as well as different interpretations of the evidence. Substantially divergent approaches allow empirical comparisons of validity and utility [36, 37].

The main changes in the ICD-11 include gaming addiction, chronic pain, burnout syndrome, stroke, sexual health, allergies, alternative medicine, and antibiotic resistance.

In the new ICD-11 edition, gaming addiction is classified as a mental disorder for the first time. This disorder is characterized as behavioral addiction to gaming - online and offline. We will be able to diagnose it if there is a violation of personal, family, social behavior, which is observed for at least 12 months.

The problematic use of social media by adolescents is a growing phenomenon, often associated with an increased perception of psychological stress and comorbid 
mental disorders such as depression. ICD-11 presented criteria for Internet use (and Internet gaming) disorders. In the ICD-11, gaming disorders are included for the assessment of disorders associated with social media use. Cognitive behavioral symptoms of gambling disorders and their negative consequences support the assumption that gaming addiction on social networks deserves its own conceptualization in the context of the ICD-11 behavioral addictions and may contribute to the development of standardized conceptualization in the future [38].

The next ICD-11 novel deals with chronic pain. The International Association for the Study of Pain (IASP) has developed a classification of chronic pain, which has been included in the ICD-11 code "MG30". In the studies of Korwisi B., Barke A., Rief W. et al. ICD-11 chronic pain classification provides the results of an Internet survey of 177 healthcare professionals from all countries using the WHO-FiT platform. After training on the chronic pain coding website, participants evaluated 18 diagnostic codes from the 2017 frozen version of the ICD-11 and 12 cases describing conditions with chronic pain. Correctness, ambiguity and perceived coding complexity were compared between ICD-11 and ICD-10. The applicability of the incidence rules for the ICD-11 was checked. $43.0 \%$ of correct diagnoses of chronic pain made according to the ICD10 and $63.2 \%$ according to the ICD-11 were received. Especially in cases where chronic pain is considered a symptom of the underlying disease, ICD-11 (63.5\%) gives more accurate diagnoses than ICD-10 (26.8\%). Coding of cases was on average $83.9 \%$ accurate, with only $1.6 \%$ of cases having difficulty. Morbidity rates were applied correctly in $74.1 \%$ of cases. In terms of coding, ICD-11 outperforms ICD-10 in every way, offering better coding accuracy, complexity, and ambiguity for chronic pain conditions [39].

The WHO emphasizes that burnout syndrome is not an innovation of the ICD-11. According to the ICD-11, burnout is a syndrome that occurs due to chronic stress in the workplace. That is, chronic stress at work can lead to burnout. This definition was also in the previous edition - the ICD-10. Occupational burnout is discussed in the section "Factors affecting health or contact with health services." This section describes the reasons for patients seeking medical attention. These causes are not classified as diseases or health conditions. The main signs of burnout: loss of energy, a feeling of exhaustion; psychological distancing from work, negative and pessimistic thoughts about work increases; reduced professional efficiency. Burnout syndrome is used in a professional context and cannot be used to describe experiences in other areas of life [1].

Approaches to the classification of stroke have changed in the ICD-11: it is now a disease of the brain, not the circulatory system. The next innovation is that in the ICD11 the whole section is devoted to sexual health [1].

In addition, in the ICD-11 there are [1]:

- specific symptoms for diagnosing post-traumatic stress disorder have been clarified and complex post-traumatic stress disorder has been added;

- allergies are listed as diseases of the immune system: such grouping will improve the understanding of immune responses; 
- alternative medicine is presented in one section - for easy calculation of statistics on diseases and conditions, concepts that originated in ancient Chinese medicine, and are now widely used in China, Japan, Korea and other countries;

- special codes for antibiotic resistance have been introduced to help more accurately measure the effectiveness of drugs around the world [1].

The transition to the ICD-11 takes time. Understanding the new concepts that are being introduced is a key starting point. In ICD-11, five new chapters have appeared, as a result of which the numbering of chapters has changed [40].

New chapters of the ICD-11 [40]:

- Chapter 03: Diseases of the blood or blood-forming organs;

- Chapter 04: Immune system disorders (conditions affecting the immune system and conditions affecting the blood, now in two separate chapters);

- Chapter 07: Sleep and Wakefulness Disorders;

- Chapter 17: Conditions related to sexual health;

- Chapter 27: Alternative medicine.

New chapter of the ICD-11 on alternative medicine: non-traditional medicine is used all over the world, but it has never been classified as ailment before [40].

The new chapter on sexual health in the ICD-11 brings together conditions that were previously classified in other ways (for example, gender disparity was listed as mental health conditions) or described differently. In addition to the United States, other countries have established the WHO ICD by creating their own code sets. However, with the help of the ICD-11, countries can define a specific linearization for the national needs of the skin area, which can save years and save significant costs in implementation. This is one of the reasons for optimism regarding the timing and expectation of an "earlier" rather than a "later" date for the introduction of the ICD-11 into medical practice [40].

Many problems arising when using the ICD-10 are proposed to be solved with the help of the ICD-11. As an example, ICD-11 includes subsections on HIV, simplified diabetes coding, types of melanomas, and better classification of valve disease [40].

The ICD-11 will also affect the expansion codes. Another new ICD-11 concept is the code clustering feature, which combines two or more codes to describe a diagnostic object. Promising for practical health care is that the implementation of the ICD-11 does not require significant financial costs, pursues budgetary funding, availability of education and software. There are electronic resources available (the WHO browser) where individuals and organizations can begin to review the content changes and view guidance on transitioning to the ICD-11. It is a valuable exercise for programmers, managers, and especially IT staff to assess requirements and get started with software vendors [40].

The next task was to compare ICD-11 and ICD-10 on mental and behavioral disorders after the use of psychoactive substances (Table 1).

Thus, the Table 1 shows that in the ICD-11 code 6C "Disorders caused by the use of surfactants" no longer has the code F "Mental and behavioral disorders....". The names of the sections of the ICD-11 are abbreviated and concise, the diagnoses are given in essence. 
Table 1. ICD-10 and ICD-11 codes for mental and behavioral disorders as a result of psychoactive substances use (author's text)

\section{ICD-10 code \\ ICD-11 code}

F10-F19. Mental and 6C Disorders caused by the use of psychoactive substances behavioral disorders due to the use of psychoactive substances F10. Mental and 6 behavioral disorders due to alcohol consumption

F11. Mental and 6C43 Diseases caused by opioids use behavioral disorders due to opioid use

F12. Mental and behavioral disorders due to cannabinoids use

F13. Mental and behavioral disorders due to the use of sedatives or hypnotics

\begin{tabular}{|c|c|}
\hline $\begin{array}{l}\text { F14. Mental and } \\
\text { behavioral disorders due } \\
\text { to cocaine use }\end{array}$ & 6C45 Disorders caused by cocaine use \\
\hline $\begin{array}{l}\text { F15. Mental and } \\
\text { behavioral disorders due } \\
\text { to the use of other } \\
\text { stimulants, including } \\
\text { caffeine }\end{array}$ & $\begin{array}{l}\text { 6C46 Disorders caused by stimulants use, including } \\
\text { amphetamines, methamphetamine or methcathinone }\end{array}$ \\
\hline & $\begin{array}{l}\text { 6C47 Diseases caused by the use of synthetic cathinones } \\
\text { 6C48 Disorders caused by caffeine consumption }\end{array}$ \\
\hline $\begin{array}{l}\text { F16. Mental and } \\
\text { behavioral disorders due } \\
\text { to the use of } \\
\text { hallucinogens }\end{array}$ & 6C49 Disorders caused by the use of hallucinogens \\
\hline $\begin{array}{l}\text { F17. Mental and } \\
\text { behavioral disorders due } \\
\text { to tobacco use }\end{array}$ & 6C4A Disorders caused by nicotine use \\
\hline $\begin{array}{l}\text { F18. Mental and } \\
\text { behavioral disorders due } \\
\text { to the use of volatile } \\
\text { solvents }\end{array}$ & 6C4B Violations caused by volatile inhalants \\
\hline
\end{tabular}




\begin{tabular}{|l|l|}
\hline $\begin{array}{l}\text { F19. Mental and } \\
\text { behavioral disorders due } \\
\text { to the use of several } \\
\text { drugs and other } \\
\text { psychoactive substances }\end{array}$ & $\begin{array}{l}\text { 6C4F Disorders caused by the use of several of these } \\
\text { psychoactive substances, including drugs }\end{array}$ \\
\hline & $\begin{array}{l}\text { 6C4C by } \\
\text { methylenedioxymethamphetamine or related drugs, } \\
\text { including tenamphetamine (e.g., ecstasy) }\end{array}$ \\
\hline & $\begin{array}{l}\text { 6C4D Dissociative disorders including ketamine and } \\
\text { phencyclidine (e.g., telazole) }\end{array}$ \\
\hline & $\begin{array}{l}\text { 6C4E Disorders caused by the use of other specified } \\
\text { psychoactive substances, including drugs (combination } \\
\text { drugs with narcotic drugs, psychotropic substances and } \\
\text { precursors as active pharmaceutical ingredients, e.g., } \\
\text { corvalol, codeterpine) }\end{array}$ \\
\hline $\begin{array}{l}\text { F55. Abuse of non- } \\
\text { addictive substances }\end{array}$ & $\begin{array}{l}\text { 6C4G Disorders caused by the use of unknown or } \\
\text { indeterminate psychoactive substances } \\
\text { 6C4H Disorders caused by the use of non-psychoactive } \\
\text { substances (e.g., analgesics) }\end{array}$ \\
\hline 6A41 Catatonia caused by substances or drugs \\
\hline & $\begin{array}{l}\text { 6C4Y Other specified disorders, caused by the use of } \\
\text { psychoactive substances }\end{array}$ \\
\hline
\end{tabular}

The coding of the section in the ICD-11 starts with code 6 C 40 .

It should be noted that the numerical indicator 6 indicates the ordinal number according to mortality and morbidity statistics.

The diagnoses of mental and behavioral disorders due to cannabinoid use have been expanded: 6C41 Diseases caused by cannabis use and 6C42 Diseases caused by synthetic cannabinoid use.

Anxiolytics added to the ICD-10 F13 diagnosis: 6C44 Disorders caused by sedatives, hypnotics, or anxiolytics

The diagnosis of the ICD-10 F15 is expanded by positions on surfactant stimulants, including amphetamines, methamphetamine or methcathinone (6C46), synthetic cathinones (6C47).

Psychoactive substance tobacco in the ICD-11 was replaced by psychoactive substance nicotine (6C4A) and volatile solvents by volatile inhalers (6C4B).

The ICD-11 clarifies the diagnosis of multiple psychoactive substances. Code $6 \mathrm{C} 4 \mathrm{~F}$ indicates that disorders caused by the use of several of these psychoactive substances, including drugs, are classified.

The ICD-11 adds diagnoses related to health disorders due to the use of methylenedioxymethamphetamine or related drugs, including tenamphetamine (6C4C); dissociative drugs, including ketamine and phencyclidine (6C4D); other psychoactive substances, including drugs (6C4E); unknown or undetermined surfactants (6C4G). 
The ICD-11 highlights section 6C4H - Disorders caused by the use of nonpsychoactive substances (e.g., analgesics).

Section 6C, Psychoactive Substance Disorders, of the ICD-11 also contains new diagnoses 6A41 "Substance or Drug Catatonia" and 6C4Y "Other Specified Psychoactive Substance Disorders".

The use of the ICD-11 contributes to the development of medical informatics in terms of information systems, big data, new knowledge (informatics, librarianship and behavior studies). Behavioral studies (from English) are behavioral sciences that study cognitive processes within organisms and behavioral interactions between organisms in the natural world [41].

The prospects for the ICD-11 classification system are emerging [42]:

communicative value between clinicians and their patients, as well as between clinicians and the families of their patients;

ease of use;

clinical value from practical application.

In general, significant changes have been made to the ICD-11. It is a different and more powerful health information system based on a formal ontology, designed to be embedded in modern information technology infrastructures and flexible enough for future modifications and use with other classifications and terminologies. The rules for combining of the ICD-11 categories allow for a qualitative description of cases in comparison with the ICD-10. Control mechanisms in the ICD-11 are quite relevant and modern. Information systems in the ICD-11 have changed more since the release of ICD-10 in the last century [43-45].

Conclusions. An organizational and legal, clinical and pharmacological study of the ICD-11 on the its changes was conducted. New ways of marking disease codes and new functions in the ICD-11 were highlighted. The construction of the ICD-11 structure based on cluster coding (a new way of marking codes) was mentioned, which allows to connect the main diagnostic codes with advanced clinical indicators. Found that for the first time, that the ICD-11 has become a fully electronic publication that provides access to more than seventeen thousand diagnostic categories that contain more than 100,000 terms of the medical diagnostic index. The new ICD-11 concept of linearization for the national needs of each country was mentioned, which will save budget expenditures. In the new edition of the ICD-11, for the first time, gambling addiction is classified as a mental disorder - behavioral addiction to online and offline gambling. The list of the ICD-11 short stories also includes the classification of: chronic pain, burnout, stroke, sexual health, post-traumatic stress disorder, allergies, alternative medicine, etc. ICD-11 is a more powerful health information system based on a formal ontology, designed to integrate information technology into modern infrastructures. A comparison with the ICD-10 on mental and behavioral disorders due to the use of psychoactive substances was made. The ICD-11 has been identified as having a more comprehensive (twenty codes) list of disease diagnosis codes, and in the ICD-10 the section on mental and behavioral disorders due to substance use has eleven core codes. The prospects of using of the ICD-11 in medical practice were indicated. 


\section{References.}

1. Occupational burnout is a phenomenon, not a disease: What was actually approved in ICD-11. Ministry of Health of Ukraine. URL: https://moz.gov.ua/article/news/profesijne-vigorannja---javische-a-ne-hvoroba-schonaspravdi-zatverdili-v-mkh-11.

2. Occupational burnout is considered a syndrome, and gaming addiction is considered a disease. LexInform. URL: https://lexinform.com.ua/zakonodavstvo/profesijne-vygorannya-vyznayutsyndromom-a-igrovu-zalezhnist-hvoroboyu/

3. Krasnov V.N. ICD-11 as a Paradigm Shift Phase in the Classification of Mental Disorders. Consortium Psychiatricum. 2021. Vol. 2. Issue 2. P. 72-75. DOI:10.17816/CP70. URL: https://consortium-psy.com/jour/article/view/70

4. Reed G.M., First M.B., Kogan C.S. et al. Innovations and changes in the ICD11 classification of mental, behavioural and neurodevelopmental disorders. World Psychiatry., 02.01.2019. Vol.18. N.1. P. 3-19. DOI: 10.1002/wps.20611. URL: https://www.ncbi.nlm.nih.gov/pmc/articles/PMC6313247/

5. Hayduchok I.G., Shapovalova V.O., Ishcheikin K.E. et al. Pharmaeconomic approaches for pharmacotherapy of Rheumatoid arthritis. Likars'ka Sprava. 2021. N. 1-2. P. 54-63. DOI: 10.31640/JVD.1-2.2021(8)

6. Tukhar I., Shapovalova V., Shapovalov V. et al. Pharmacological view on the problem of comorbidity in the pharmacotherapy of chronic pancreatitis. Science Review. Vol. 3. No. 38. P. 1-5. DOI: 10.31435/rsglobal_sr/30072021/7591

7. Chuiev Y., Shapovalova V. Interdisciplinary pharmacoeconomic study of pharmacotherapy of cupping of drunk forms of alcohol dependence: clinical and pharmacological, organizational, legal and marketing experiment. SSP Modern Pharmacy and Medicine. 2021. Vol. 1. N. 2. P. 1-12. URL: https://doi.org/10.53933/sspmpm.v1i2.24.

8. Shapovalov V., Butko L., Shapovalov V. Organizational and legal study of quarantine restrictions in the spread of coronavirus disease in Ukraine. SSP Modern Pharmacy and Medicine. 2021. Vol. 1. N. 2. P. 1-12. URL: https://doi.org/10.53933/sspmpm.v1i2.23.

9. Shapovalova V., Shapovalov V., Shapovalov V. et al. Experience of the department of medical and pharmaceutical law, general and clinical pharmacy of the Kharkiv medical academy of postgraduate education concerning the educational process during the quarantine period caused by COVID-19. Actual Problems of Medicine and Pharmacy. 2021. Vol.2. N.2. P. 1-20. https://doi.org/10.52914/apmp.v2i2.33.

10. Hayduchok I., Shapovalov V. Forensic pharmacy and medicine: risks for pharmacotherapy of addiction and countering of illegal circulation of psychoactive substances in the COVID-19 pandemic. 2021. SSP Modern Pharmacy and Medicine. Vol. 1. N. 2. P. 1-28. URL: https://doi.org/10.53933/sspmpm.v1i2.32.

11. Shapovalova V.A., Zbrozhek S.I., Shapovalov V.V. et al. Forensic pharmacy: some risk factors in the formation of addictive health disorders. Acta Scientific 
Pharmaceutical Science. 2021. V. 4. Iss. 1. P. 7-12. DOI: 10.3180/ ASPS.2020.05.0651.

12. Shapovalov V. (Jr.), Gudzenko A., Komar L. et al. Concerning the importance of forensic and pharmaceutical researches to improve patients' accessibility to medicines. Pharmacia. 2017. Vol. 65. N. 2. P. 23-29. URL: http://bsphs.org/wpcontent/uploads/2017/07/Shapovalov.pdf.

13. Shapovalov V. (Jr.), Gudzenko A., Shapovalova V. at. el. Forensic and pharmaceutical study of the presence of a causal link between the degree of alcohol abuse and qualification level of the respondents. Pharmacia. 2017. Vol. 66. N. 3. P. 31-39. URL: http://bsphs.org/wp-content/uploads/2017/11/Shapovalov.pdf.

14. Zbrozhek S.I., Shapovalova V.A., Shapovalov V.V. et al. Organizational and legal research of indicators of incidence and prevalence of diabetes mellitus in countryside areas. Annals of Mechnikov Institute. 2017. N. 1. P. 44-53. URL: http://www.imiamn.org.ua/journal/1_2017/zmist1_2017.html.

15. Shapovalov V. (jr.), Zbrozhek S., Gudzenko A. et al. Organizational and legal analysis of the pharmaceutical provision for the most common diseases of society. International Journal of Pharmaceutical Sciences Review and Research. 2018. Vol. 51. N. 1. P. 118-124. URL: http://globalresearchonline.net/journalcontents/v511/18.pdf.

16. Shapovalov V.V. (Jr.), Zbrozhek S.I., Shapovalova V.O. et al. Organizational and legal evaluation of availability of medicines' circulation for cancer patients Pharmacia. 2018. Vol. 65. N. 2. P. 17-22. URL: http://bsphs.org/?magasine=organizational-and-legal-evaluation-of-availability-ofmedicines-circulation-for-cancer-patients.

17. Shapovalov V.V. Organizational and legal approaches to the development of combined drugs based on psychoactive substances for the prevention and treatment of drug addiction. Dissertation for Doctor of Pharmaceutical Sciences degree. Specialty 15.00.01 "Drug technology and organization of pharmaceutical business". Kyiv, 2005. 44 p. URL: http://irbis-nbuv.gov.ua/ASUA/0011146.

18. Kuznetsova T.V. Drug support for alcohol dependence therapy: dissertation for $\mathrm{PhD}$ in Pharmacy degree. Specialty 15.00.01 "Drug technology and organization of pharmaceutical business". Kyiv, 2006. 24 p. URL: http://irbisnbuv.gov.ua/ASUA/0081252.

19. Shapovalov V.V., Gudzenko A.A., Zbrozhek S.I. et al. Forensic and pharmaceutical analysis of addictive morbidity because of the use of psychotropic psychoactive substances in Ukraine (retrospective aspect). Annals of Mechnikov Institute. 2018. No. 3. P. 41-44. DOI: 10.5281/zenodo.1456544. URL: http://www.imiamn.org.ua/journal/3_2018/PDF/9.pdf.

20. Gutorov O.I. Improving the regulatory framework for the circulation of psychoactive substances in the private sector of the regional pharmacy network. Dissertation for $\mathrm{PhD}$ in Pharmacy degree. Specialty 15.00.01 "Drug technology and organization of pharmaceutical business". Kharkiv, 2007. 20 p. URL: http://irbisnbuv.gov.ua/ASUA/0004817. 
21. Bondarenko V.V. Scientific substantiation of features of expert support of circulation of psychoactive substances. Dissertation for PhD in Pharmacy degree. Specialty 15.00.01 "Drug technology and organization of pharmaceutical business". Kharkiv, 2008. 22 p. URL: http://irbis-nbuv.gov.ua/ASUA/0108941.

22. Shapovalov V. (Jr.), Gudzneko A., Shapovalova V. et al. Forensic and pharmaceutical analysis of addictive morbidity because of the use of narcotic psychoactive substances in Ukraine (retrospective aspect). International Journal of Pharmaceutical Sciences and Research. 2018. Vol. 3. Is. 3. P. 22-25. URL: http://www.pharmacyjournal.net/archives/2018/vol3/issue3.

23. Vasina $\mathrm{Yu} . \mathrm{V}$. Organizational research of forensic pharmacy to counteract the narcotization of young people with psychoactive substances. Dissertation for $\mathrm{PhD}$ in Pharmacy degree. Specialty 15.00.01 "Drug technology and organization of pharmaceutical business". Kharkiv, 2009. 24 p. URL: http://irbisnbuv.gov.ua/ASUA/0090297.

24. Osyntseva A.O. Scientific substantiation of the principles of pharmaceutical correction of polydrug addiction on the basis of forensic pharmacy. Dissertation for $\mathrm{PhD}$ in Pharmacy degree. Specialty 15.00.01 "Technology of medicines, the organization of pharmaceutical business and forensic pharmacy". Kyiv, 2020. 24 p. URL: http://irbis-nbuv.gov.ua/ASUA/1476729.

25. Malinina N.G. Forensic and pharmaceutical research of the control and permitting system to increase the level of state control over the circulation of precursors in Ukraine. Dissertation for $\mathrm{PhD}$ in Pharmacy degree. Specialty 15.00.01 "Drug technology and organization of pharmaceutical business". Kharkiv, 2010. 24 p. URL: http://irbis-nbuv.gov.ua/ASUA/0034175.

26. Petrenko V.O. Organizational and legal research of drug correction of nicotine addiction. Dissertation for PhD in Pharmacy degree. Specialty 15.00.01 "Drug technology and organization of pharmaceutical business". Kharkiv, 2010. 24 p. URL: http://irbis-nbuv.gov.ua/ASUA/0036699.

27. Kuryzheva O.O. Forensic pharmaceutical prevention of addictive addiction and drug crime among minors. Dissertation for $\mathrm{PhD}$ in Pharmacy degree. Specialty 15.00.01 "Drug technology and organization of pharmaceutical business". Kharkiv, 2011. 24 p. URL: http://irbis-nbuv.gov.ua/ASUA/0048391.

28. Peresypkin O.V. Forensic and pharmaceutical substantiation of circulation of drugs with psychoactive properties of different nomenclature and legal groups. Dissertation for $\mathrm{PhD}$ in Pharmacy degree. Specialty 15.00.01 "Drug technology, organization of pharmaceutical business and forensic pharmacy". Kharkiv, 2013. 24 p. URL: http://irbis-nbuv.gov.ua/ASUA/0066533.

29. Negretsky S.M. Forensic pharmaceutical substantiation of organizational measures to provide drugs for drug addicts addicted to cannabinoids (F12). Dissertation for PhD in Pharmacy degree. Specialty 15.00.01 "Drug technology, organization of pharmaceutical business and forensic pharmacy". Kyiv, 2016. 24 p. URL: http://irbisnbuv.gov.ua/ASUA/0575291.

30. Shapovalov V.V. Forensic pharmaceutical bases of search of ways of pharmacocorrection of drug patients with deviant behavior within the limits of the state 
concept of counteraction to drug addiction and drug crime. Dissertation for Doctor of Pharmaceutical Sciences degree. Specialty 15.00.01 "Drug technology, organization of pharmaceutical business and forensic pharmacy". Kyiv, 2017. 44 p. URL: http://irbisnbuv.gov.ua/ASUA/0089067.

31. Movsisyan A.G. Prevention of addictive dependence on the basis of forensic pharmacy in the formation of a healthy lifestyle among youth. Dissertation for $\mathrm{PhD}$ in Pharmacy degree. Specialty 15.00.01 "Drug technology, organization of pharmaceutical business and forensic pharmacy". Kyiv, 2017. 24 p. URL: http://irbisnbuv.gov.ua/ASUA/0695217.

32. Shuvera O.V. Forensic pharmaceutical bases of improvement of measures of counteraction at alcohol dependence (F 10.2). Dissertation for $\mathrm{PhD}$ in Pharmacy degree. Specialty 15.00.01 "Drug technology, organization of pharmaceutical business and forensic pharmacy". Kyiv, 2017. 24 p. URL: http://irbisnbuv.gov.ua/ASUA/1256723.

33. ICD-11 for Mortality and Morbidity Statistics (Version: 05/2021). URL: https://icd.who.int/browse11/1-m/en.

34. Mendelevich V.D. The sick list on pedophilia and disability on drug addiction. Neurology Bulletin. 2017. Is. XLIX. No. 3 P. 5-10. URL: https://journals.ecovector.com/1027-4898/article/view/14060.

35. Youmans K. Background \& overview of ICD-11 before implementation in 2022. YES-him consulting. 18.10.2021.

URL: https://yes-himconsulting.com/icd-11-overview/

36. First M.B., Gaebel W., Maj M. et al. An organization- and category-level comparison of diagnostic requirements for mental disorders in ICD-11 and DSM-5. Wiley Online Library. 12 January 2021. URL: https://doi.org/10.1002/wps.20825.

37. Gutiérrez F., Peri J.M., Gárriz M. Integration of the ICD-11 and DSM-5 Dimensional Systems for Personality Disorders into a Unified Taxonomy with Nonoverlapping Traits. Front. Psychiatry. 06 April 2021. URL: https://doi.org/10.3389/fpsyt.2021.591934.

38. Paschke K., Austermann M.I., Thomasius R. ICD-11-Based Assessment of Social Media Use Disorder in Adolescents: Development and Validation of the Social Media Use Disorder Scale for Adolescents. Front. Psychiatry. 22.04.2021. URL: https://doi.org/10.3389/fpsyt.2021.661483.

39. Korwisi B., Barke A., Rief W. et al. Chronic pain in the $11^{\text {th }}$ revision of the International Classification of Diseases users' questions answered. PAIN. 03.12.2021. DOI:

10.1097/j.pain.0000000000002551.

URL:https://journals.lww.com/pain/abstract/9000/classification_of_chronic_pain_for the.98059.aspx

40. Gatehouse S. ICD-11. Prep: Examining Prominent Changes in Preparation for the Transition. ICD10 monitor. URL: https://www.icd10monitor.com/icd-11-prepexamining-prominent-changes-in-preparation-for-the-transition.

41. Chen D., Zhang R., Zhao H., Feng J. A Bibliometric Analysis of the Development of ICD-11 in Medical Informatics. JHE. 2019. DOI: https://doi.org/10.1155/2019/1649363. 
42. Tracy M., Tiliopoulos N., Sharpe L. The clinical utility of the ICD-11 classification of personality disorders and related traits: A preliminary scoping review. The Australian \& New Zealand Journal of Psychiatry (ANZJP). Vol. 55. Issue 9. URL: https://doi.org/10.1177/00048674211025607.

43. ICD-11: an international classification of diseases for the twenty-first century/ Harrison J.E., Weber S., Jakob R. et al. BMC Med Inform Decis Mak 21, 206 (2021). URL: https://doi.org/10.1186/s12911-021-01534-6

44. Reed G.M., First M.B., Kogan C.S. et al. Innovations and changes in the ICD11 classification of mental, behavioral and neurodevelopmental disorders. Wiley Online Library. 02 January 2019. URL: https://doi.org/10.1002/wps.20611.

45. Harrison J.E., Weber S., Jakob R. et al. ICD-11: an international classification of diseases for the twenty-first century. BMC Med Inform Decis Mak. 2021. N.21. 206 p. URL: https://doi.org/10.1186/s12911-021-01534-6. 